\title{
Factors Effecting Omnichannel Customer Experience: Evidence from Fashion Retail
}

\author{
Hadiqa Riaz ${ }^{1}$, Umair Baig ${ }^{2}$, Ieva Meidute-Kavaliauskiene ${ }^{3, *(1)}$ and Hassaan Ahmed ${ }^{4}$ \\ 1 Department of Business Studies, Bahria University, Karachi 75420, Pakistan; hadiqariaz.bukc@bahria.edu.pk \\ 2 Department of Commerce, Benazir Bhutto Shaheed University, Karachi 75660, Pakistan; \\ umaiirbaig@gmail.com \\ 3 Department of Business Technologies and Entrepreneurship, Faculty of Business Managments, \\ Vilnius Gediminas Technical University, Sauletekio al. 11, LT-10223 Vilnius, Lithuania \\ 4 Department of Business Administration, Salim Habib University, Karachi 74400, Pakistan; \\ hassaan.ahmed@shu.edu.pk \\ * Correspondence: ieva.meidute-kavaliauskiene@vilniustech.lt
}

Citation: Riaz, H.; Baig, U.; Meidute-Kavaliauskiene, I.; Ahmed, H. Factors Effecting Omnichannel Customer Experience: Evidence from Fashion Retail. Information 2022, 13, 12. https://doi.org/10.3390/ info13010012

Academic Editors: Joanna Paliszkiewicz and Marcin Ratajczak

Received: 21 November 2021

Accepted: 19 December 2021

Published: 28 December 2021

Publisher's Note: MDPI stays neutral with regard to jurisdictional claims in published maps and institutional affiliations.

Copyright: (C) 2021 by the authors. Licensee MDPI, Basel, Switzerland. This article is an open access article distributed under the terms and conditions of the Creative Commons Attribution (CC BY) license (https:// creativecommons.org/licenses/by/ $4.0 /)$.

\begin{abstract}
This research work was designed to investigate the changing dynamics of the retail landscape driven by omnichannel retailing, and to determine the effects on the omnichannel customer's experience. The role of omnichannel customer behavior in the relation between omnichannel retailing and customer experience was assessed through a survey of 265 omnichannel customers of different fashion retail brands in Pakistan. The results of partial least squares structural equation modeling (PLS-SEM) showed a strong mediating effect of omnichannel customer behavior in channeling the drivers of omnichannel retailing towards an enhanced customer experience. Omnichannel retailing helps to enhance the customer experience via determinants of omnichannel integration, order fulfilment, usability and seamlessness. The research findings underpin the positive significant effect of all factors of omnichannel retailing on the customer experience. Among the four omnichannel retailing constructs, seamlessness emerged as a major direct and indirect contributor, followed by omnichannel integration and usability dimensions. Notwithstanding the small sample size, this research contributes to the omnichannel retailing landscape of Pakistan's fashion retail industry by suggesting a functional approach for creating a fully integrated shopping experience and omnichannel strategies for fashion brands. Furthermore, it will also provide brands an opportunity to strengthen their customers' experience throughout the buying channel.
\end{abstract}

Keywords: omnichannel retailing; omnichannel integration; omnichannel seamlessness; omnichannel fulfilment; omnichannel usability; omnichannel customer behavior; omnichannel customer experience

\section{Introduction}

Approximately 150 years ago, rapid urbanization disrupted the retail sector, driven by industrialization, which helped department stores to blossom. This was followed by the development of the automobile, which helped people to quickly move around cities and suburbs, thus nurturing shopping malls. Later in the nineteenth century, the rise of discount stores and category killers transformed the retail environment. Although these developments and changes in the retail sector did not allow any of the previous formats to fade away, they readily transformed and reshaped their predecessor's value-creating narrative [1,2].

Similarly, digital disruption is now reshaping the retailing landscape and, similar to the case of previous disruptions, the changes are redefining consumer expectations. Internet technologies and the dot-com bubble lured a large number of e-retailers to online platforms with high expectations of gaining a first-mover competitive advantage [3]. As a result of the continuous development of technology and digital platforms, the conventional retail environment, in which customers shopped from separate silos, morphed into a completely 
new single and seamless shopping experience, i.e., the "Omnichannel Experience". In this new environment, consumers can shop by alternating between e-commerce, physical, and $\mathrm{m}$-commerce platforms [4]. Although multichannel retailing focuses on more than one sales channel, which have little or no interaction between each other, the omnichannel retail model works on the integration and unification of all touch points to enable customers to move seamlessly without any break in the experience [5].

Omnichannel retailing is defined as a retail strategy that integrates all sales channels to facilitate customers to have a seamless experience by eliminating the traditional boundaries between them [6]. Customers are fickle and want consistent experiences specifically targeted to their needs. Although many retailers have implemented omnichannel strategies, there is a noticeable gap between customer-perceived value and retailer omnichannel performance [7]. A recent study found that omnichannel retailers are not serving customers properly with their existing omnichannel system [8]. Another study showed that, although many retailers state that they are geared towards omnichannel retailing, they prefer to operate each channel on its own [9]. Therefore, the constant change in customer behavior incentivizes many retailers to serve the needs of these new customers by offering them a coherent retail experience that is neither offline nor online, but an integrated omnichannel experience. Both scholars and industry professionals have come to recognize that the customer experience is one of the key differentiating factors in determining the customer decision process and the success of the retailer omnichannel strategy.

Therefore, it is imperative for retailers to determine how to improve the omnichannel customer experience, and identify the factors that can help smooth operations and interaction fluency. Seminal research has previously been conducted to examine the importance of customer experience in an omnichannel environment. Recent studies on omnichannel retailing have examined omnichannel integration [10], operations [11-13] and shopping value $[14,15]$. Moreover, prior studies on omnichannel customer experience highlighted key characteristics of the customer experience [16-18] and also determined its impact on shopping intention.

Several studies have highlighted the omnichannel customer experience as a subdimension in their research [19]. Regardless of the ever-increasing importance of omnichannel retailing and customer experience, there is little evidence regarding the omnichannel factors that build a consistent customer experience. In addition, there is a dearth of studies that simultaneously focus on omnichannel customer behavior and customer experience. Omnichannel customer behavior has emerged as a significant driver of a seamless customer experience and shopping intention [20]. Modern retailers continuously optimize omnichannel strategies, making it more essential to pay close attention to changing trends in customer behavior that will influence their experience. Furthermore, there is limited literature available related to omnichannel retailing in Pakistan. Recent studies have mainly focused on the development and potential of omnichannel retail [21]. In addition, there is a need to develop a bottom-up understanding of the omnichannel factors that drive a cohesive customer experience, with a close consideration of omnichannel customer behavior. To fill the above-mentioned gap, this research employed a quantitative research design to investigate the factors associated with omnichannel retailing that lead customers towards a positive omnichannel experience, with the mediating role of omnichannel customer behavior. This research was conducted in the context of omnichannel fashion retail in Pakistan. Omnichannel retailing has emerged as a highly prominent medium for fashion brands, as they seek to reach customers beyond their brick-and-mortar presence. Pakistan's fashion retail brands are currently striving to delve into lifestyle brands by adopting omnichannel strategies and engaging customers on multiple touch points.

There are a number of areas where this study can make significant contributions. The primary contribution of this research is identifying the enablers of omnichannel retailing that enable the building of a true omnichannel customer experience. In addition, we conceptualize a framework by linking omnichannel customer behavior and customer experience. This extends the current research and tests the dimension of omnichannel 
customer behavior in creating a positive customer experience. As a practical implication, this study can help fashion retailers to redesign omnichannel strategies that deliver better shopping value in every channel, and eventually create a personalized and progressive customer experience.

The remainder of the paper is organized in the following manner. The next section presents a detailed review of the literature, in addition to the conceptual framework and hypothesis development. Section 3 provides details about the research design and data collection instrument. Section presents a detailed analysis of the study findings and discussion of the results.

\section{Literature Review}

\subsection{Omnichannel Retailing: Concept and Factors}

With the growth of digitalization, the retailing industry has experienced a radical change in terms of serving customers [22,23]. The concept of omnichannel retailing was first coined by [24], who transformed the retailing paradigm to one level up from "MultiChannel Retailing" or "Cross-Channel Retailing". As defined by [25], omnichannel retailing is a business model that combines all existing channels as blended touch points to influence customer purchase decisions. This integrated model involves multiple channels and creates a single strategy that is implemented across all channels to build more coordinated and customer-centric experience [26]. Also endorsed that omnichannel retailing entails the solution of "Integrated management of the various customer touch points in such a manner that customer experience across all interactions can be maximized, whereas [27] inculcates that a real omnichannel strategy solely focused on consumer value throughout their buying experiences. Ref. [28] supported the same inception and explored how fashion retailers use omnichannel shopping functionalities to attain a strong base of customers. The study appraised the channel consolidation process and suggested that retailers update their customers on the efficacy of using multiple channels. Another study by [29] revealed that understanding customer needs and expectations is the first building block of true omnichannel experience. In order to streamline customer experience, it is important to know that all customers are not identical to one another; therefore, there is a need to design different customer profiles for an effective omnichannel strategy. Recent studies also advocate to emphasize on factors that enhance right customer experience by pulling customer behaviour in the same direction [30]. Thus, to better capture the omnichannel customer experience, the conceptualization of omnichannel retailing needs to be explored.

\subsection{Omnichannel Customer Experience}

The omnichannel customer experience is a multichannel approach that streamlines all customer interaction in a unified way to create an integrated experience [31]. Creating positive customer experience pushed many retailers to have a better understanding of the overall customer journey [32]. In recent times, customer experience has become a capital element in the success of fashion retailers. For that reason, effective implementation of omnichannel strategies and absolute knowledge of customer touchpoints are essential for gaining a competitive advantage in the industry [33]. According to [34], omnichannel customer experience is a multichannel approach through which retailers provide consistent, integrated and seamless experience, regardless of the channel used. The author has conceptualized omnichannel customer experience by corroborating the five dimensions of customer experience, which are connectivity, flexibility, integration, consistency and personalization. Ref. [35] through a mixed method approach, suggested that retailers extend their traditional brick and mortar experience and ensure that end-to-end online and offline journeys should substantially focus on targeting audience needs and preferences to mitigate challenges and conflict in usage experience [36]. Corroborated that the buying cycle of omnichannel customers is often unpredictable, since they have a myriad touchpoints by which to research, select and purchase products [37]. Supported these findings and postulated that omnichannel customers follow a non-linear sales funnel and have a greater 
tendency to assimilate various stages of the buying process. Therefore, it is imperative for retailers to pivot on strategies that serve a non-linear buying journey to create a distinctive customer experience.

Ref. [38] Identified channel integration and seamlessness as indispensable factors in developing an omnichannel customer experience. It streamlines all the interaction and enables customer to engage with the retailer through several channels and stimulate fluent transition within the same interaction [39]. Stressed taking advantage of the omnichannel distribution and fulfillment network to enhance customer experience. Retailers that adopt fulfillment strategies are able to exceed centralized distribution, reduce back orders and ensure that products are available across different channels [40]. Indicated the importance of unified omnichannel strategy in fostering relevant brand experience. A well-designed omnichannel strategy will cultivate the capabilities to offer consistent customer experience and will eradicate confusing experiences that dissatisfy customers. Thus, in order to achieve a unified customer experience, retailers need to embrace a holistic omnichannel strategy that melds the benefits of physical platforms with the value-added experience of online shopping.

\subsection{Omnichannel Integration}

Cross channel integration and the shift towards omnichannel strategy enables retailers to retain their customers while cohesively integrating the best of both offline and online consumerism [41]. Defined channel integration as a coordination and orchestration among various omnichannel operations and strategies including purchase and return of products, promotions, price and distribution in such a way that the experience of interacting across all touchpoints become more efficient and rewarding than engaging solely with a single channel. According to [25], omnichannel integration falls under two categories. First, integrating online channels or information with offline channels. Second, integrating offline channels or information with online channels. Ref. [39] found that channel integration was one of the key determinants of a successful omnichannel strategy, and claimed that without an absolute integration of silo channels, the multichannel model could not transform into the omnichannel model. In recent years, many researches have drooled over the augmented market value aligned with the implication of omnichannel integration [42]. It vanished the distinction between offline and online customer touch points where customers can easily transfer their shopping between devices [43]. Omnichannel retailing takes a wider perspective on creating synchronization and integration across channels to optimize customer experience with overall functional proficiency [44]. The recent literature on channel integration articulates various dimensions of omnichannel integration on the basis of unification between online and offline resource, channel process consistency and order fulfillment with integrated planning which are the prerequisite for customer experience [45]. Omnichannel integration is likely to have an influence on omnichannel customer behaviour and customer experience. With the support of the above literature, we have developed the following hypothesis.

Hypothesis 1. Omnichannel integration has a positive influence on omnichannel customer experience within fashion retail.

\subsection{Omnichannel Seamlessness}

With the rise of technological devices, customers demand omnichannel experience that is accessible, convenient and seamless. In omnichannel retailing, if customers easily resume their purchase actions where they end up, the experience will be seamless, but at the same time if customers fail to reconnect their task or have to undergo the complete process when moving to a new channel, the experience will fall apart [46]. According to [26] omnichannel seamlessness is the extent to which a customer believes shopping from online, offline and mobile channels to be flexible, consistent and convenient. Where omnichannel integration focuses on the interminglation and merger of interaction chan- 
nels, omnichannel seamlessness specifies the quality of the omnichannel customer journey where the movement between channels entails zero or negligible fences or interruption for users. Nurturing omnichannel seamlessness requires reshaping customer value proposition elements and activities in terms of product availability across different sales channels [47]. Aligned the same point and suggested that retailers offer a seamless customer journey by removing perceived resistance and to ensure collaborative channel integration to maximize the advantage of omnichannel retailing. Ref. [48] signified that customers with a positive shopping experience attempted to purchase online. In his cross-sectional study, he determined that past online purchase experience directly linked to ease of use and performance expectancy [49]. Acknowledged that retailers can only create self-efficacy in shoppers by providing them with seamless shopping experience.

Omnichannel strategies should incorporate strong administration tools that increase user efficiency. Discovered the importance of fluid operational functionality across channels. The author forced omnichannel retailers to provide customized shopping options to maintain consistent brand identity. Ref. [50] explored how customers habitually do not complete their purchase using a single channel or in one go. The reason behind this fragmented behaviour usually involves external interruption or the selection of other suitable channels. Thus, a comprehensive understanding of when and why customers switch across different channels is essential to streamline customer interaction and seamless customer journey. We thus hypothesize the relation between omnichannel seamlessness and omnichannel customer experience as follows.

Hypothesis 2. Omnichannel seamlessness has a positive influence on omnichannel customer experience within fashion retail.

\subsection{Omnichannel Fulfillment}

The growing importance of omnichannel retail has led to the need for realign and enhanced fulfillment strategies. Similar to multichannel distribution network, research on omnichannel fulfillment embeds multiple distribution systems with integrated planning [51,52]. The smooth flow of order fulfillment is one of the daunting challenges in omnichannel retailing. Retailers with effective omnichannal strategies are in a position to successfully mitigate distribution issues and outperform competitors [53]. Early studies on fulfillment suggest that retailers could adopt their current logistic support system to carry out the operations of integrated omnichannel. However, in reality, retailers need to redesign their fulfilment strategies with an advanced management and infrastructure system [54]. A well-executed omnichannel strategy involves a streamline fulfillment process and ensures that the product is ordered, allocated and shipped to the final customer as conveniently as possible.

According to [7], omnichannel fulfillment is the order handling strategy based on retailer logistics capabilities that control and maintain flow of inventory within an integrated distribution network that is paramount for consistent customer experience. The demandside perspective of the omnichannel approach emphasizes the need for seamless and consistent order fulfillment experience irrespective of the channel of interaction [55]. The change in customer behavioral patterns demands greater convenience. Customers increasingly expect to be able to shop from anywhere, anytime and through any device; to receive their products in store or have them delivered at home; and to be able to move between the channels seamlessly [56]. In their mixed-method study identified that faster omnichannel fulfillment requires better use of inventory and variety of order completion strategies, regardless of its geographical barriers. For a streamlined order fulfillment process, omnichannel retailers should adopt multiple options to deliver items to the final customer. So long as one fulfillment option fails to meet the operations, the retailer can switch to other routes. Ref. [57] point out retailer internal business policy, carrier compliance and the flexibility of distribution software as the key success factors of omnichannel fulfillment. 
Omnichannel fulfillment is a mutual support method that manages customer orders received from a loop of multiple channels. These channels may involve, buy online return in store (BORIS), and buy online pick up in store (BOPIS), home delivery or any other approach to deliver the order to the final customer [58]. Specifically, from a supply chain perspective, omnichannel fulfillment exemplifies the unification of warehouse and physical distribution systems to satisfy customer demand and enable retailers to nurture positive customer experience. Based on the above literature, the below hypothesis has been developed to measure the influence of omnichannel fulfillment on omnichannel customer experience.

Hypothesis 3. Omnichannel fulfilment has a positive influence on omnichannel customer experience within fashion retail.

\subsection{Omnichannel Usability}

Different sales channels have different performance measures in terms of usage and customer needs. Ref. [58] identified that successful customer experience is the main task for omnichannel retailers. Ref. [25] inculcate that omnichannel usability is when a customer is offered optimized features and fluid experience when moving from one channel to another channel. Customers want to be served by the retailer who helped them to accomplish their purchasing task easily. Ref. [59] focused on the consistency and standards of online and offline stores to optimize experience for the main target audience. Omnichannel customers expect cohesive and consistent experience regardless of how or where a customer reaches out. They want to move their shopping cart between devices and prefer to customize their choices. The millennial customer does not want to use singular channel strategy, but rather prefers to access multiple channels at one time. The authors discussed the shopping behaviour of Spanish customers using multiple channels of Zara stores, and found that the most imperative factors that trigger customer purchase intention in an omni shopping setting depends on the performance expectancy, effort expectancy and the level of personal innovativeness of the retailers [18]. Omnichannel not only offers simultaneous customer interaction across channels, but also establishes symbiotic management of the available channels to ensure integrated customer experience based on streamline channel transition. Omnichannel usability goes beyond omnichannel seamlessness as the core value of omnichannel usability is not only seamless transition across channels but it also focuses on the availability and optimization of omnichannel functionalities (e.g., user interface). We thus hypothesize the relation between omnichannel usability and omnichannel customer experience.

Hypothesis 4. Omnichannel usability has a positive influence on omnichannel customer experience within fashion retail.

\subsection{Omnichannel Customer Behaviour}

The adoption of omnichannel retailing has a real impact on consumer buying. The evolution of the brick and click business model increases purchase frequency as customers can conveniently use multiple sales channels to complete their purchase $[60,61]$, talked about the overhaul in contemporary shopper's behaviour. He expounded on the notion that in recent years, customer buying behaviour has made it obvious that they expect more fluency and ease in buying than ever before. In order to complete one purchase, customers are likely to follow a rigors procedure by using multiple channels. According to [61], in an omni-channel environment, customer behaviour is the study of customer actions and how they behave throughout their buying journey in terms of searching, comparing, receiving and returning products. The approaches of "showrooming" (search the product in brick-and-mortar store but buy online) and "webrooming" (find the product in online store but purchase offline) has become customer interaction style with retailers and exhibit their contemporary behaviour as an omnichannel customer. In parallel, ref. [62] noticed that modern retailers have realized customer changing behaviour and in pursuit of offering 
seamless experience, they have instigated the "select and collect" option, a strategy that facilitates customers to buy online and pick up from the physical store.

According to [63] as customer behaviour is uninfluenced by retailers, there is a dire need to make possible differentiation. As per [64], omnichannel customers go through five stages in their path to purchase. These stages follow different actions that customers perform to purchase a product and encompasses searching, comparing, receiving items and possibly returning them as well. Omnichannel shopping provides different channels to complete a purchase. The author described shopper constitutional activities that are established in all purchases (e.g., purchasing and receiving), whilst other actions are malleable and can be performed numerous times or deserted completely. Omnichannel customers are growing as a global opportunity [65]. These new customers want to access multiple channels to search for the best products, customer services and look for inexpensive options during their purchase journey to avail the unique benefits offered by different channels [66]. Moreover, omnichannel customers possess extensive brand knowledge and think they know more about the product than the sales professional and show more control over their purchases. Changing trends in omnichannel customer behaviour pose a great challenge for retailers. Moreover, multiple channel integration makes customer journey more complex and unpredictable. Customer rapid shift towards showrooming and webrooming behaviour has also greatly influenced retailer's ability to provide seamless customer experience from an early product search to after sales services [54]. Recent studies on omnichannel customer behaviour mainly focus on purchase intention and channel choice [64]. In order to create positive omnichannel customer experience, omnichannel retailers must focus on omnichannel customer behaviour during and after an omnichannel transaction. To understand how omnichannel customer behaviour impacts omnichannel customer experience, this study uses omnichannel customer behaviour as a mediator between omnichannel retailing and customer experience, proceeding with the following hypothesis.

Hypothesis 5. Omnichannel customer behaviour has a positive influence on omnichannel customer experience within fashion retail.

The hypothesis predicting the mediating role of omni customer behaviour has been further separated into the following sub-hypothesis to investigate the mediating role of omnichannel customer behaviour on the relation between each omnichannel retailing dimension and omnichannel customer experience in the context of fashion retail in Pakistan.

Hypothesis 5 (H5a). Omnichannel customer behaviour mediates the relationship between omnichannel integration and omnichannel customer experience within fashion retail.

Hypothesis 5 (H5b). Omnichannel customer behaviour mediates the relationship between omnichannel seamlessness and omnichannel customer experience within fashion retail.

Hypothesis 5 (H5c). Omnichannel customer behaviour mediates the relationship between omnichannel fulfillment and omnichannel customer experience within fashion retail.

Hypothesis $\mathbf{5}$ (H5d). Omnichannel customer behaviour mediates the relationship between omnichannel usability and omnichannel customer experience within fashion retail.

\section{Methodology}

\subsection{Sample Selection and Sampling Technique}

Moreover, ref. [67] argue that a sample between 200-400 respondents should be acquired to reduce biases and to generate accurate and reliable results. For determining sample size, an online calculator is also used with a 5\% error margin and $95 \%$ confidence level. Therefore, the sample size of 265 omnichannel shoppers was satisfactory to run statistical tests and to generate significant results. After studying the dynamics of the 
population and prior research thoroughly, the respondents were selected for an online survey under the following criteria in order to gain the probability of selection in a sample.

$\bigcirc \quad$ The respondent must have used more than one sales channel (online shopping from a desktop or mobile device, or in a brick and mortar store).

$\bigcirc \quad$ Have purchased fashion related items from any of the selected case companies.

$\bigcirc \quad$ Judgmental and convenient sampling techniques were used to distribute questionnaires as the sampling frame of complete omnichannel shoppers in Pakistan is hard to construct.

\subsection{Case Companies}

The following criteria have been adopted to select fashion retail companies for the research.

- The fashion retailer must work within the Pakistani market.

- The fashion retailer must have more than one sales channel (brick and mortar store, website for e-commerce and mobile app for shopping).

- The retailer must be dealing in fashion related products.

Table 1 shows the names of 20 fashion retail companies and the criteria on which they were selected on.

Table 1. Case Companies Selection Criteria (Fashion Retailers).

\begin{tabular}{cccccc}
\hline Retailer & $\begin{array}{c}\text { Operate within } \\
\text { Pakistan }\end{array}$ & $\begin{array}{c}\text { Related to } \\
\text { Fashion Industry }\end{array}$ & \multicolumn{2}{c}{ Using More than One Sales Channel } \\
\hline Bonanza Satrangi & $\checkmark$ & $\checkmark$ & $\checkmark$ & Brick and Mortar Store & Mobile Web Store \\
\hline Khaadi & $\checkmark$ & $\checkmark$ & $\checkmark$ & $\checkmark$ & $\checkmark$ \\
\hline Ethnic & $\checkmark$ & $\checkmark$ & $\checkmark$ & $\checkmark$ & $\checkmark$ \\
\hline Sapphire & $\checkmark$ & $\checkmark$ & $\checkmark$ & $\checkmark$ & $\checkmark$ \\
\hline Al karam Studio & $\checkmark$ & $\checkmark$ & $\checkmark$ & $\checkmark$ & $\checkmark$ \\
\hline Outfitters & $\checkmark$ & $\checkmark$ & $\checkmark$ & $\checkmark$ & $\checkmark$ \\
\hline Kapray & $\checkmark$ & $\checkmark$ & $\checkmark$ & $\checkmark$ & $\checkmark$ \\
\hline Gul Ahmed & $\checkmark$ & $\checkmark$ & $\checkmark$ & $\checkmark$ & $\checkmark$ \\
\hline J. & $\checkmark$ & $\checkmark$ & $\checkmark$ & $\checkmark$ & $\checkmark$ \\
\hline Nishat Linen & $\checkmark$ & $\checkmark$ & $\checkmark$ & $\checkmark$ & $\checkmark$ \\
\hline Levis & $\checkmark$ & $\checkmark$ & $\checkmark$ & $\checkmark$ & $\checkmark$ \\
\hline Keyseria & $\checkmark$ & $\checkmark$ & $\checkmark$ & $\checkmark$ & $\checkmark$ \\
\hline Chen One & $\checkmark$ & $\checkmark$ & $\checkmark$ & $\checkmark$ & $\checkmark$ \\
\hline Edenrobe & $\checkmark$ & $\checkmark$ & $\checkmark$ & $\checkmark$ & $\checkmark$ \\
\hline Generation & $\checkmark$ & $\checkmark$ & $\checkmark$ & $\checkmark$ \\
\hline Sana Safinaz & $\checkmark$ & $\checkmark$ & $\checkmark$ & $\checkmark$ \\
\hline Limelight & $\checkmark$ & $\checkmark$ & $\checkmark$ & $\checkmark$ \\
\hline Asim Jofa & $\checkmark$ & $\checkmark$ & $\checkmark$ & $\checkmark$ & $\checkmark$ \\
\hline Threads n Motive & $\checkmark$ & $\checkmark$ & $\checkmark$ & $\checkmark$ & $\checkmark$ \\
\hline Zeen & $\checkmark$ & $\checkmark$ & $\checkmark$ & $\checkmark$ \\
\hline
\end{tabular}

\subsection{Measuring Instrument and Data Collection}

We decided to adopt a quantitative approach since we have to undergo in depth analysis of omnichannel retailing and omnichannel customer experience throughout their 
buying journey. Data were collected between August and October 2021 with the help of a properly structured five-point Likert scale survey questionnaire to explore the efficiency of omnichannel retailing and to determine whether these selected fashion retail companies provide holistic and seamless experience to its customers. We distributed 627 survey questionnaires, out of which 265 questionnaires were completed and scrutinized for further analysis. All items relating to our study constructs were adopted from scholarly research. Items adopted were modified as required to fit in the criteria of the study. Omnichannel retailing dimensions (such as omnichannel integration, omnichannel seamlessness, omnichannel usability and fulfillment) were evaluated by using 4 items and were adopted from the studies of $[27,63]$. To measure omnichannel customer behaviour, 6 items were used, and the main concept was adopted from the study of [10]. Finally, omnichannel customer experience was measured by using 6 items, and the scale was adopted from the recent study of [4].

\subsection{Data Analysis Methods}

The data were analyzed using SmartPLS. Construct reliability and validity (Discriminant and convergent) were examined through a regular PLS Algorithm; subsequently, the bootstrapping resampling method was used to test the statistical significance of various hypothesized relationships. In addition, standardized root mean square residuals (SRMR) and Normed fit indices (NFI) were used to assess model fitness. PLS structural equation modelling was performed because of its capability to model multiple relationships concurrently and curb the endogeneity problem.

\subsection{Research Model}

This study develops a conceptual framework (See Figure 1) to determine the factors of omnichannel retailing that create the omnichannel customer experience. Omnichannel factors also hypothesized the influence on omnichannel customer behaviour, which is conceptualized as a mediating variable in this research. The below diagram presents a proposed research model and displays five postulated research hypotheses related to direct and indirect effect.

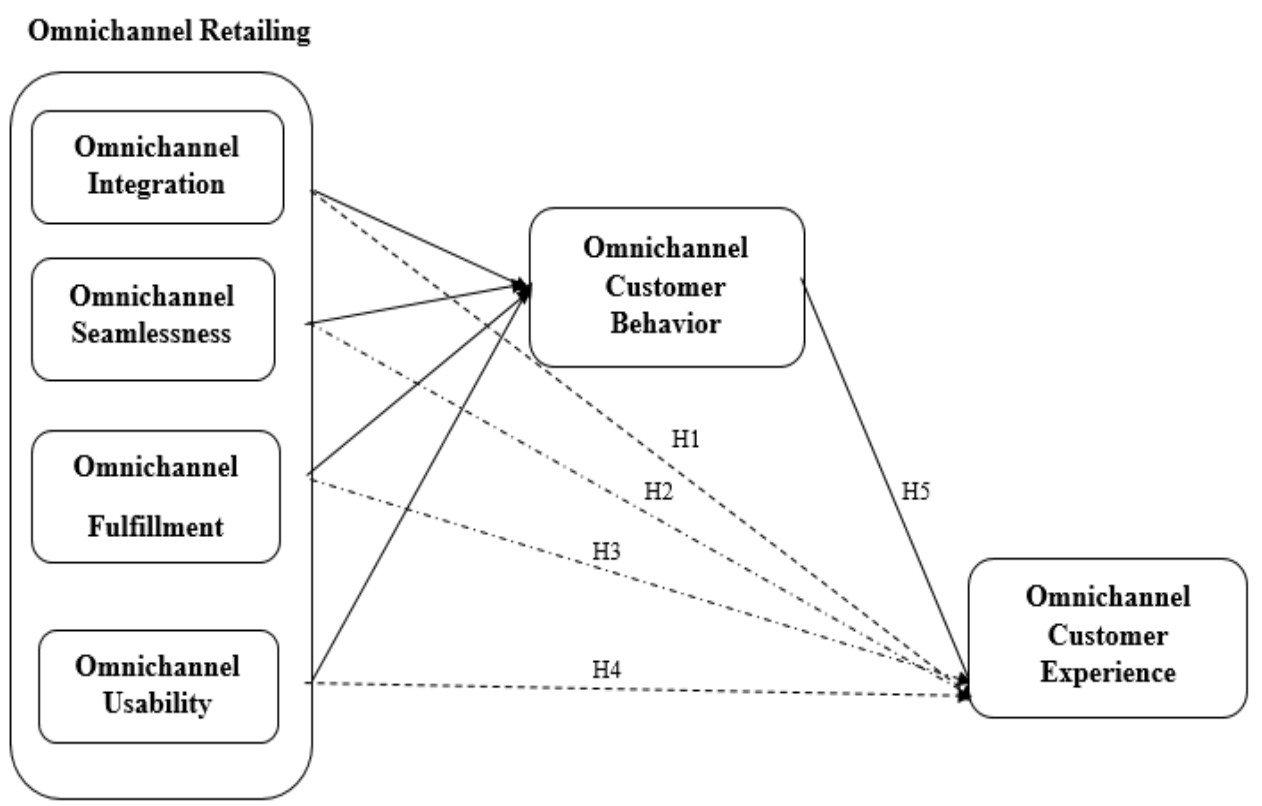

Figure 1. Research Model. 


\section{Results and Discussion}

\subsection{Respondents Demographic Profiling}

At the beginning of the questionnaire, filtering questions were added to ensure that respondents had shopped from selected fashion retail brands using more than one sales channel. Out of 265 omnichannel customers, 43.2\% were male, whereas $58.8 \%$ were female omnichannel customers. The survey respondents were dominated by the (21-30) age group, which made up $64.9 \%$ of the total sample size. Moreover, $62.4 \%$ of the respondents reported that they did not have any particular buying pattern for fashion products. Moreover, the rest of the participants showed different purchasing frequencies by using multiple sales channels.

\subsection{Indicator Reliability and Convergent Validity}

The data were analyzed using several steps. In the first step, we examined the reliability and convergent validity of the proposed model. The indicator of reliability was ascertained through the indicator of outer loading, whereas convergent validity was examined through the average variance extracted. Table 2 shows the results of the indicator reliability, composite reliability, Cronbach's alpha and the values of the (AVE) average variance extracted. The results depict that indicator factors meet the criteria of $>0.70$ as defined by [68]. This denotes that all items load substantially on their own construct and explains a considerable amount of variance by their relevant latent variables. As per the findings of [69], the composite reliability (CR) and Cronbach's alpha values should be greater than 0.7; in the below table, the CR constructs and alpha values meet the suggested threshold and confirm the internal consistency of the data. Convergent validity that shows a positive correlation of items of the same construct should be greater than AVE $>0.5$. Thus, the resultant values of convergent validity for each variable are greater than 0.5 and affirm the AVE benchmark. It should be pointed out that five items were excluded due to lower factor loading $(<0.7)$ after evaluating its idle impact on composite reliability and average variance extracted.

Table 2. Indicator Reliability and Convergent Validity.

\begin{tabular}{|c|c|c|c|c|c|}
\hline Constructs & Indicators & Factor Loading & Cronbach Alpha & $\begin{array}{c}\text { Composite } \\
\text { Reliability (CR) }\end{array}$ & $\begin{array}{l}\text { Average Variance } \\
\text { Extracted (AVE) }\end{array}$ \\
\hline \multirow[t]{4}{*}{ Omnichannel Integration } & CI1 & 0.71 & 0.714 & 0.82 & 0.53 \\
\hline & $\mathrm{CI} 2$ & 0.74 & & & \\
\hline & $\mathrm{CI} 3$ & 0.77 & & & \\
\hline & $\mathrm{CI} 4$ & 0.70 & & & \\
\hline \multirow[t]{4}{*}{ Omnichannel Seamlessness } & SEM1 & 0.74 & 0.75 & 0.83 & 0.50 \\
\hline & SEM2 & 0.70 & & & \\
\hline & SEM3 & 0.75 & & & \\
\hline & SEM4 & 0.72 & & & \\
\hline \multirow[t]{4}{*}{ Omnichannel Fulfilment } & FUL1 & 0.77 & 0.70 & 0.80 & 0.50 \\
\hline & FUL2 & 0.70 & & & \\
\hline & FUL3 & 0.71 & & & \\
\hline & FUL4 & 0.65 & & & \\
\hline \multirow[t]{4}{*}{ Omnichannel Usability } & USA1 & 0.72 & 0.71 & 0.82 & 0.53 \\
\hline & USA2 & 0.75 & & & \\
\hline & USA3 & 0.73 & & & \\
\hline & USA4 & 0.71 & & & \\
\hline
\end{tabular}


Table 2. Cont.

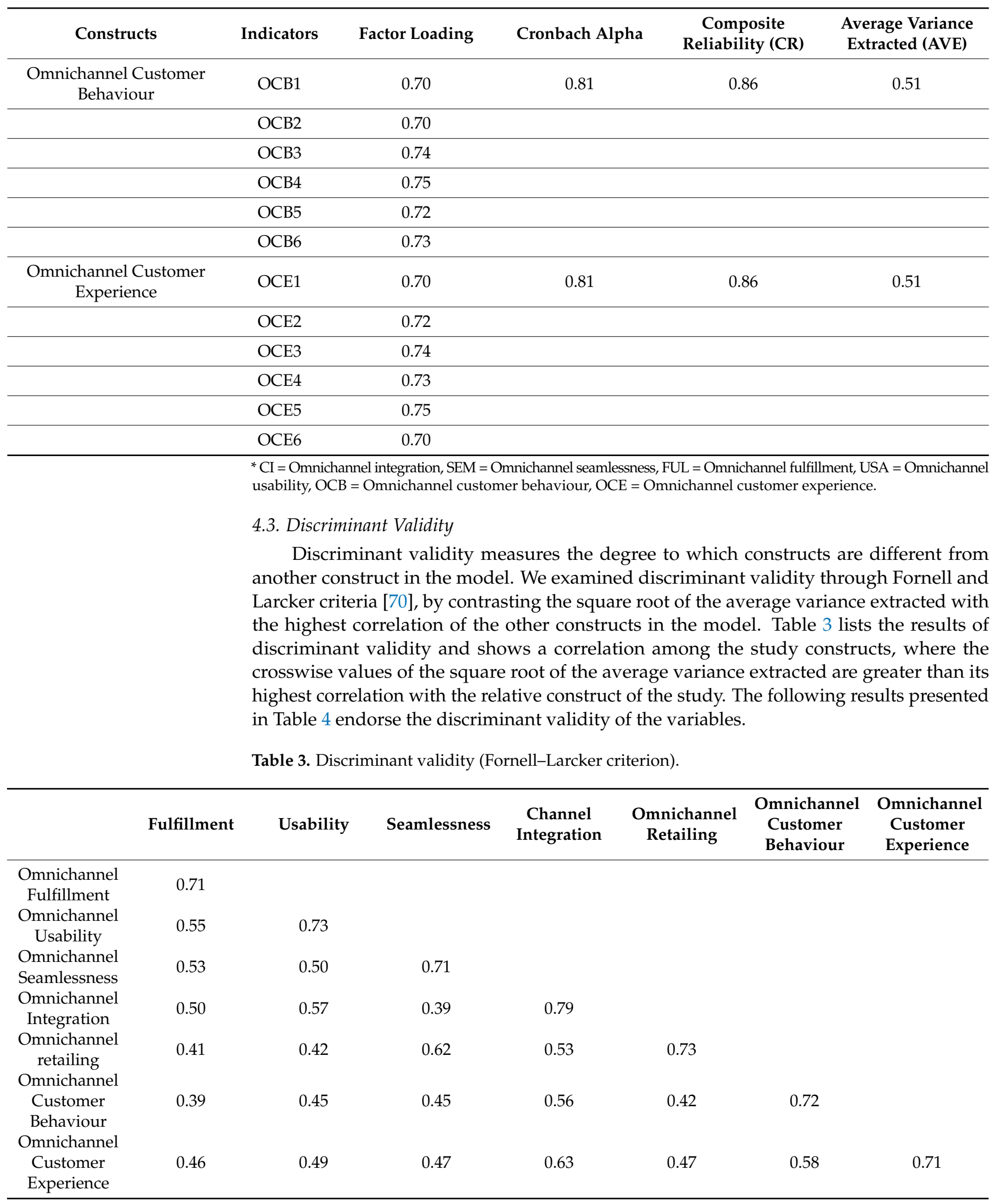


Table 4. Coefficient of Determination and Predictive Relevance.

\begin{tabular}{lcc}
\hline & Q2 & R2 \\
\hline Omnichannel Customer Behaviour & 0.32 & 0.16 \\
\hline Omnichannel Customer Experience & 0.47 & 0.23 \\
\hline
\end{tabular}

\subsection{Assessment of Coefficient of Determination and Predictive Relevance (Blindfolding)}

The results of the coefficient of determination (R2) and predictive relevance (Q2) of the study's endogenous variables (omnichannel customer behaviour and omnichannel customer experience) are presented in Table 4. R2 explains the amount of variance in endogenous variables explained by the corresponding exogenous latent variables present as weak, moderate or substantial for the values of $0.25,0.50$ and 0.70 , respectively. The values of Q2 exhibit in Table 5 are greater than zero (0.32 and 0.47) and indicates that the partial least square path model has substantial predictive relevance for the study constructs. Thus, our results present strong congruence with omnichannel synchronization, omnichannel seamless, omnichannel fulfillment and omnichannel usability.

Table 5. Model fitness Results.

\begin{tabular}{ccc}
\hline & Estimated Model & Threshold \\
\hline SRMR & 0.09 & $<0.1$ \\
\hline NFI & 0.92 & $>0.9$ \\
\hline
\end{tabular}

Source: Prepared by Author.

\subsection{Model Fitness}

Standardized root mean square residual (SRMR) and normed fit indices are used to ascertain the goodness of fit of the path model. NFI determines the fit between hypothesized and proposed models of the study. NFI values greater than 0.9 consider meeting model fitness criteria. SRMR provides the average proportion of the discrepancies between the resultant and expected correlation as a benchmark measure of the fitness criteria of the study model. The standardized root mean square residual (SRMR) value must be $<0.1$ to meet the standard measures of fitness. The path model fitness examined by SRMR and NFI indices are presented in Table 5.

The values for SMRS and NFI indices of the structural model are 0.09 and 0.9, respectively, which indicates that standardized root means square residual and normed fit index are in the threshold range and confirms the model fitness of the model. The predicted and observed measures are noticed to be equivalent and validates the goodness of fit $(\mathrm{GoF})$ of the study model.

\subsection{Path Analysis}

After determining the reliability and validity of the constructs and establishing model fitness, the structural relation among constructs were investigated. The path analysis was conducted by analyzing two models, in the first model the overall influence of omnichannel retailing on omnichannel customer experience through omnichannel customer behaviour was estimated. In the second stage, we investigated the impact of omnichannel retailing with individual constructs on omnichannel customer experience directly and through omnichannel customer behaviour as a mediator.

The results of the proposed relationship measuring direct and indirect effects are exhibited in Table 6 . The results of the structural model signify that overall omnichannel retailing $(\beta=0.630, p<0.000)$ posits a significant impact on omnichannel customer experience. The large value of the omnichannel retailing path coefficients posits a significant impact on omnichannel customer experience. These results are in line with the number of previous studies [4]. It is evident from [5] that omnichannel retailing directly enhance omnichannel customer experience, as it not only differentiated these retailers in the market 
but also paved ways to earn competitive advantage over online shopping stores through utilizing their physical stores presence. Subsequently, results also affirmed the substantial impact of omnichannel customer behaviour $(\beta=0.569, p<0.000)$ in directing the effect of omnichannel retailing towards the achievement of true omnichannel customer experience. By combining these results, it can be implied that omnichannel platforms help retailers to engage more customers and to provide them with what they want, and through whatever channel they want, which in turn becomes instrumental for cultivating a positive customer experience. The results are also reflected with those concluded in pertinent studies. For instance, [10] noted that omnichannel customer behaviour is the strong driver of customer experience in omnichannel context and aspiring lifestyle experience. Likewise, $[25,26]$ suggested that customers prefer integration of the physical and online stores and stated that these immersions along with mobile shopping development would enrich customer shopping experience.

Table 6. Results of Direct and Indirect Effect.

\begin{tabular}{|c|c|c|c|c|}
\hline & Path Coefficient & T-Value & $p$-Value & Decision \\
\hline $\begin{array}{l}\text { Omnichannel retailing } \rightarrow \\
\text { Omnichannel Customer Experience }\end{array}$ & 0.630 & 13.412 & 0.000 & Supported \\
\hline $\begin{array}{l}\text { Omnichannel retailing } \rightarrow \\
\text { Omnichannel Customer Behaviour } \rightarrow \\
\text { Omnichannel Customer Experience }\end{array}$ & 0.569 & 13.335 & 0.000 & Supported \\
\hline $\begin{array}{l}\text { Omnichannel Customer Behaviour } \rightarrow \\
\text { Omnichannel Customer Experience }\end{array}$ & 0.337 & 7.655 & 0.000 & Supported \\
\hline $\begin{array}{l}\text { Omnichannel integration } \rightarrow \\
\text { Omnichannel Customer experience }\end{array}$ & 0.197 & 7.574 & 0.000 & Supported \\
\hline $\begin{array}{c}\text { Omnichannel seamlessness } \rightarrow \\
\text { Omnichannel customer experience }\end{array}$ & 0.221 & 9.269 & 0.000 & Supported \\
\hline $\begin{array}{l}\text { Omnichannel fulfillment } \rightarrow \\
\text { Omnichannel customer experience }\end{array}$ & 0.164 & 7.373 & 0.000 & Supported \\
\hline $\begin{array}{l}\text { Omnichannel usability } \rightarrow \\
\text { Omnichannel customer experience }\end{array}$ & 0.189 & 9.373 & 0.000 & Supported \\
\hline $\begin{array}{l}\text { Omnichannel integration } \rightarrow \\
\text { Omnichannel Customer Behaviour } \rightarrow \\
\text { Omnichannel Customer Experience }\end{array}$ & 0.178 & 7.991 & 0.000 & Supported \\
\hline $\begin{array}{c}\text { Omnichannel seamlessness } \rightarrow \\
\text { Omnichannel Customer Behaviour } \rightarrow \\
\text { Omnichannel Customer Experience }\end{array}$ & 0.200 & 9.319 & 0.000 & Supported \\
\hline $\begin{array}{l}\text { Omnichannel Fulfillment } \rightarrow \\
\text { Omnichannel Customer Behaviour } \rightarrow \\
\text { Omnichannel Customer Experience }\end{array}$ & 0.148 & 7.655 & 0.000 & Supported \\
\hline $\begin{array}{l}\text { Omnichannel Usability } \rightarrow \\
\text { Omnichannel Customer Behaviour } \rightarrow \\
\text { Omnichannel Customer Experience }\end{array}$ & 0.171 & 8.679 & 0.000 & Supported \\
\hline
\end{tabular}

Results related to the four omnichannel retailing constructs are highly emphasized. Findings depict a strong positive effect of omnichannel integration $(\beta=0.197, p<0.000)$ and omnichannel seamlessness $(\beta=0.221, p<0.000)$ on omnichannel customer experience. The recent tech savvy customers' demands personalized, steady and seamless experience from retailers which cannot be expected from cross channel models with several layers of customer contact. Furthermore, omnichannel fulfillment and usability were also found to be significant with positive effect size $(\beta=0.164, p<0.000)$ and $(\beta=0.189, p<0.000)$, respectively. The results of omnichannel fulfillment endorsed the consensus with [49]. A reliable omnichannel fulfillment process in terms of efficient distribution network, size of 
delivery, order tracking and number of sales personnel in brick and mortar stores expected to have a strong influence on omnichannel customer experience.

To investigate omnichannel customer behaviour mediation effects in the relation between omnichannel retailing determinants and omnichannel customer experience, we applied Baron and Kenny mediation rule of thumb. At first step the total impact of omnichannel retailing on omnichannel customer behaviour was checked. Later the effect of omnichannel customer behaviour on omnichannel customer experience, and lastly the effect of omnichannel customer behaviour on omnichannel customer experience was examined. As depicted in Figure 2 and Table 6, omnichannel retailing strongly influences omnichannel customer behaviour, as a result it significantly impacts omnichannel customer experience. These results are concurred with the research of [65] in relation to omnichannel marketing. Hence, it can be proven that omnichannel customer behaviour $(\beta=0.569$, $p<0.000$ ) partially mediates the relationship between omnichannel shopping and customer experience. To determine the mediation effect of omnichannel customer behaviour between omnichannel retailing construct (omnichannel integration, seamlessness, fulfillment and usability) and customer experience, the same method was repeated. Taking everything into account, it can be inferred that omnichannel customer behaviour has an indispensable role in enhancing omnichannel customer experience. On the other hand, these findings enable us to figure out both direct and indirect input of omnichannel factors in providing a progressive and holistic omnichannel customer experience [71,72].

\section{Omnichannel Retailing}

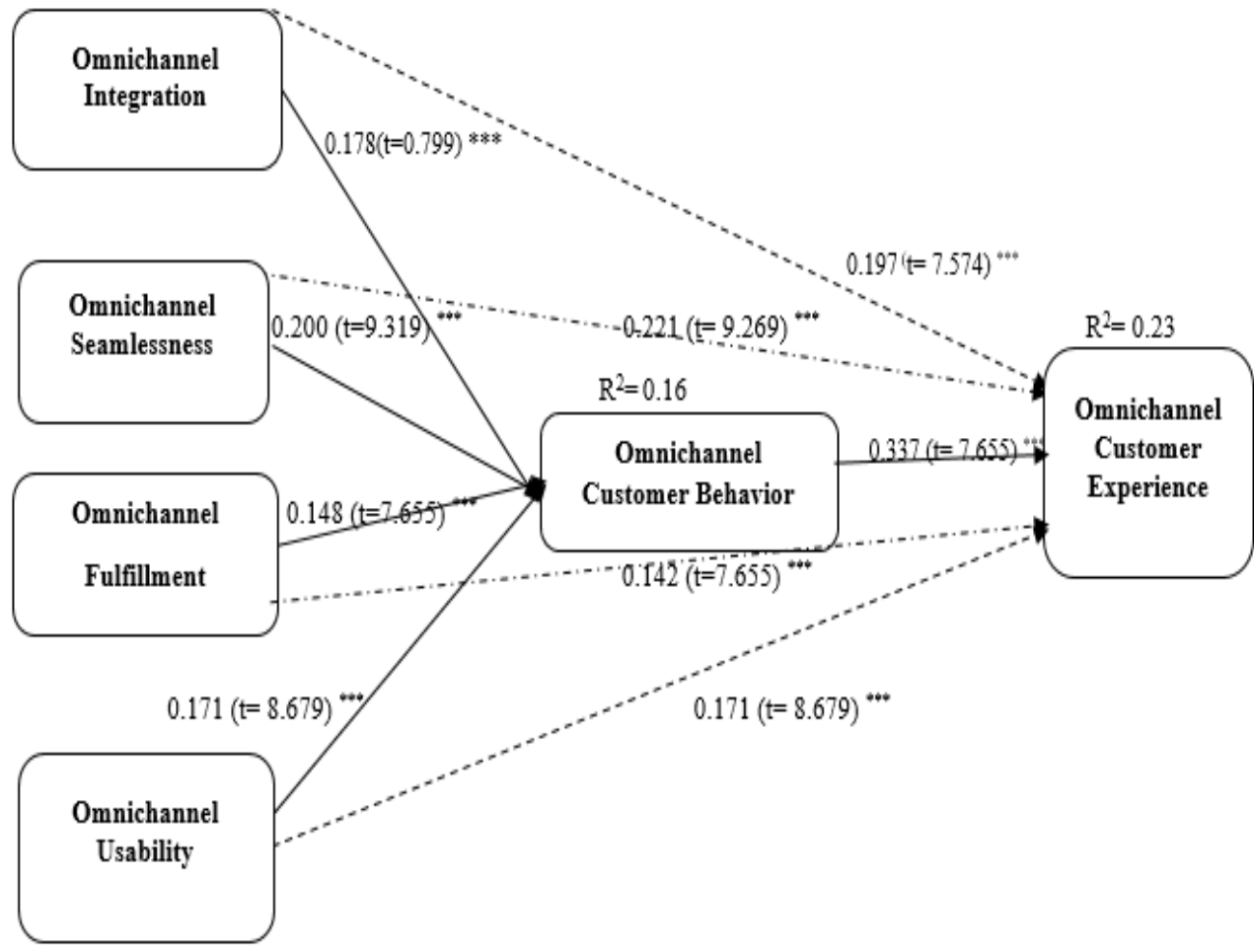

Figure 2. Partial Mediation Model of omnichannel customer behaviour on omnichannel customer experience. ${ }^{* *} p<0.001,{ }^{* *} p<0.01$, and ${ }^{*} p<0.05$ (Standardized estimate and $t$ values). Source: Prepared by Author.

\section{Conclusions}

The purpose of this study was to examine omnichannel strategies that emphasize on strengthening customer experience throughout the buying journey. Moreover, the study was conducted to ensure empirical evidence on the impact of omnichannel retailing as a whole and its factors on omnichannel customer experience. Additionally, our objective was 
to investigate the mediating role of omnichannel customer behaviour in the omnichannel retailing and omnichannel customer experience relation. The findings of the study verify that omnichannel customer behaviour is indispensable in channeling omnichannel retailing drivers towards customer experience in the context of fashion retail in Pakistan. Our results also divulge significant direct and indirect effects of omnichannel retailing enablers on customer experience. In general, these findings coincide with studied literature. However, some of the proposed relationships deviate from the extant literature mainly because of the fashion industry as a contextual factor. Herein, we proposed and tested a framework that investigates the interplays among four dimensions that drives successful management and integration of multiple sales channels, fueling a shift towards omnichannel retailing. Explicitly, these dimensions are omnichannel integration, fulfillment, usability and seamlessness. Moreover, by analyzing fashion retailer's adaptive activities in search of providing unified customer experience with the help of these dimensions, we found that fashion retailers can reap the benefits of positive customer experience by measuring and predicting omnichannel customer behaviour in terms of their individual characteristics, online to physical store and cross device shopping behaviour. In essence, this study suggests that performance expectancy of omnichannel retailing and omnichannel customer behaviour are mandatory rudiments for building customer experience. Among four omnichannel retailing dimensions, seamlessness emerged as a major direct and indirect contributor. These results advocate fashion retailers to revamp their strategies to deal with increasing customer expectations of what retailers can deliver in omnichannel shopping.

\subsection{Implications for Fashion Retailers}

The findings of this research not only concur with theoretical aspects of omnichannel retailing, but rather suggest functional approaches to create a fully integrated shopping experience and omnichannel strategies. First, Pakistani fashion retailers need to draft a streamlining fulfillment process by adopting BIOPS and click and collect models. These tactics help to maintain an optimum inclusion between offline and online sales activities, since customers are more inclined towards click and collect methods, fashion retailers can enjoy extra benefits of operational efficiency and enhanced customer experience. We observe that some of the fashion retailers do not fully utilize basic e-commerce features and mobile channels, creating hindrances in omnichannel usability and seamlessness. As the number of internet users in Pakistan is significantly increased, the transition to omnichannel retelling opens new methods for innovation and growth. Second, the study identifies and proposed fashion retailers to transform the way they contemplate omnichannel customers; moreover, individual characteristics of customer behaviour should be the central part of all omnichannel strategies. Finally, retailers working in the fashion industry should focus on the use of data analytics for a successful omnichannel initiative. Today, understanding and measuring customer behaviour is not a daunting task. Data gathered through cross channel and personalization analytics will indicate needed improvements in customer experience. Furthermore, fashion retailers should design new tactics and competencies to efficiently utilize these data collected from multiple sales channels to optimize retail operations and to rebuild a smart customer experience.

\subsection{Limitations and Future Research}

This research involves a number of limitations that also offer opportunities for upcoming research. This study adopted several omnichannel constructs to determine its influence on omnichannel customer experience, further research could incorporate other potential dimensions (e.g., connectivity, personalization, consistency) and may develop other alternative models to provide greater insight about omnichannel customer experience. From a research design perspective, our study is primarily based on survey methods of data collection. Moreover, our sample only comprised Pakistani customers, who may create disquiet about the generalizability of the study findings; therefore, it is suggested that coming studies collect data from different geographic locations to increase external 
validity. The present study gathered data based on user's omnichannel experiences, where some of the participants shared their old shopping experience or used their memory to answer survey questions. Such data may not actually depict fashion retailers' current strategies to deliver a seamless omnichannel experience. For that, we recommend future studies to adopt a mix-method approach or field experiment to critically examine the causal relationship described in the study model. Furthermore, the criteria designed for choosing survey respondents who have used more than one sales channel at least once may not truly represent the study population. Thus, future studies are suggested to compare omnichannel experience of one-time users with repeat buyers.

Author Contributions: Conceptualization, H.R. and I.M.-K.; methodology, U.B.; software, H.R. and H.A.; validation, I.M.-K. and U.B.; formal analysis, H.R.; investigation, U.B.; resources, H.A.; data curation, I.M.-K. and U.B.; writing-original draft preparation, H.R. and U.B.; writing-review and editing, I.M.-K.; visualization, H.A. All authors have read and agreed to the published version of the manuscript.

Funding: This research received no external funding.

Institutional Review Board Statement: Not applicable.

Informed Consent Statement: Not applicable.

Data Availability Statement: The data of this study are available from the authors upon request.

Conflicts of Interest: The authors declare no conflict of interest.

\section{References}

1. Hossain, T.M.T.; Akter, S.; Kattiyapornpong, U.; Dwivedi, Y. Reconceptualizing Integration Quality Dynamics for Omnichannel Marketing. Ind. Mark. Manag. 2020, 87, 225-241. [CrossRef]

2. Melacini, M.; Perotti, S.; Rasini, M.; Tappia, E. E-fulfilment and distribution in omni-channel retailing: A systematic literature review. Int. J. Phys. Distrib. Logist. Manag. 2018, 48, 391-414. [CrossRef]

3. Nagar, K.; Gandotra, P. Exploring choice overload, internet shopping anxiety, variety seeking and online shopping adoption relationship: Evidence from online fashion stores. Glob. Bus. Rev. 2016, 17, 851-869. [CrossRef]

4. Shi, S.; Wang, Y.; Chen, X.; Zhang, Q. Conceptualization of omnichannel customer experience and its impact on shopping intention: A mixed-method approach. Int. J. Inf. Manag. 2019, 50, 325-336. [CrossRef]

5. Chauhan, P.; Sarabhai, S. Customer experience quality in omni-channel banking: Identifying the factors affecting customer experience in the Indian context. Int. J. Manag. Concepts Philos. 2019, 12, 222-238. [CrossRef]

6. Beck, N.; Rygl, D. Categorization of multiple channel retailing in Multi-, Cross-, and Omni-Channel Retailing for retailers and retailing. J. Retail. Consum. Serv. 2015, 27, 170-178. [CrossRef]

7. Bhattacharya, A.; Srivastava, M. A Framework of Online Customer Experience: An Indian Perspective: An Indian Perspective. Glob. Bus. Rev. 2020, 21, 800-817. [CrossRef]

8. Hoogveld, M.; Koster, J.M. Implementing omnichannel strategies the success factor of agile processes. Adv. Manag. Appl. Econ. 2016, 6, 25.

9. Joseph, G. Sustaining Brick \& Mortar through Omnichannel: An emerging Story of Retail Business Model Convergence. Int. J. Bus. Manag. 2015, 3, 203.

10. Reinares-Lara, E.; Olarte-Pascual, C.; Pelegrín-Borondo, J.; Oruezabala, G. Omnichannel Customer Behavior: New Questions in the Age of Agility. Front. Psychol. 2021, 12, 746147. [CrossRef]

11. Jocevski, M.; Arvidsson, N.; Miragliotta, G.; Ghezzi, A.; Mangiaracina, R. Transitions towards omni-channel retailing strategies: A business model perspective. Int. J. Retail. Distrib. Manag. 2019, 47, 78-93. [CrossRef]

12. Hulland, J. Use of partial least squares (PLS) in strategic management research: A review of four recent studies. Strateg. Manag. J. 1999, 20, 195-204. [CrossRef]

13. Lee, W.Y.; Chan, T.K.; Chong, A.Y.-L.; Thadani, D.R. Customer engagement through omnichannel retailing: The effects of channel integration quality. Ind. Mark. Manag. 2018, 77, 90-101. [CrossRef]

14. Mena, C.; Bourlakis, M.; Ishfaq, R.; Defee, C.C.; Gibson, B.J.; Raja, U. Realignment of the physical distribution process in omni-channel fulfillment. Int. J. Phys. Distrib. Logist. Manag. 2016, 46, 543-561.

15. Adil, M.M. Fashioning Lifestyles. 2019. Available online: https://aurora.dawn.com/news/1143539 (accessed on 24 September 2020).

16. Keen, C.; Wetzels, M.; De Ruyter, K.; Feinberg, R. E-tailers versus retailers: Which factors determine consumer preferences? J. Bus. Res. 2004, 57, 685-695. [CrossRef]

17. Chopra, S. How omni-channel can be the future of retailing. Decision 2016, 43, 135-144. [CrossRef] 
18. Saghiri, S.; Wilding, R.; Mena, C.; Bourlakis, M. Toward a three-dimensional framework for omni-channel. J. Bus. Res. 2017, 77, 53-67. [CrossRef]

19. Fisher, M.L.; Gallino, S.; Xu, J.J. The Value of Rapid Delivery in Omnichannel Retailing. J. Mark. Res. 2019, 56, 732-748. [CrossRef]

20. Kang, J.Y.M. What drives omnichannel shopping behaviors? J. Fash. Mark. Manag. Int. J. 2019, 23, 224-238. [CrossRef]

21. Rizvi, S.M.A.; Siddiqui, D.A. Omnichannel development within the Pakistani fashion retail. J. Mark. Consum. Res. 2019, 54, 57-87.

22. Yan, B.; Chen, Y.R.; Zhou, X.T.; Fang, J. Consumer Behavior in the omni-channel supply chain under social networking services. Ind. Manag. Data Syst. 2019, 119, 1785-1801. [CrossRef]

23. Salazar, K. Seamlessness in the Omnichannel Customer Experience. 2017. Available online: https://www.nngroup.com/articles/ seamless-cross-channel/ (accessed on 24 September 2020).

24. Rigby, D.; Kirby, J. Delivering on customer expectations. In Omnichannel Retail; Harvard Business Review: New York, NY, USA, 2011; pp. 1-4.

25. Shen, X.L.; Li, Y.J.; Sun, Y.; Wang, N. Channel integration quality, perceived fluency and omnichannel service usage: The moderating roles of internal and external usage experience. Decis. Support Syst. 2018, 109, 61-73. [CrossRef]

26. Mirzabeiki, V.; Saghiri, S.S. From ambition to action: How to achieve integration in omni-channel? J. Bus. Res. 2020, $110,1-11$. [CrossRef]

27. Huré, E.; Picot-Coupey, K.; Ackermann, C.-L. Understanding omni-channel shopping value: A mixed-method study. J. Retail. Consum. Serv. 2017, 39, 314-330. [CrossRef]

28. Giannakos, M.N.; Pateli, A.; Pappas, I. Identifying the Direct Effect of Experience and the Moderating Effect of Satisfaction in the Greek Online Market. Int. J. E-Serv. Mob. Appl. 2011, 3, 39-58. [CrossRef]

29. Chen, Y.; Cheung, C.M.; Tan, C.-W. Omnichannel business research: Opportunities and challenges. Decis. Support Syst. 2018, 109, 1-4. [CrossRef]

30. Cohen, J. Statistical Power Analysis for the Behaviour al Sciences; Erlbaum: Hillsdale, NJ, USA, 1988; pp. 20-35.

31. Alnawas, I.; Hemsley-Brown, J. The differential effect of cognitive and emotional elements of experience quality on the customerservice provider's relationship. Int. J. Retail. Distrib. Manag. 2018, 46, 125-147. [CrossRef]

32. Aubrey, C.; Judge, D. Re-imagine retail: Why store innovation is key to a brand's growth in the "new normal", digitally-connected and transparent world. J. Brand Strategy 2012, 1, 31-39.

33. Henseler, J.; Ringle, C.M.; Sarstedt, M. A new criterion for assessing discriminant validity in variance-based structural equation modeling. J. Acad. Mark. Sci. 2015, 43, 115-135. [CrossRef]

34. Yrjölä, M.; Saarijärvi, H.; Nummela, H. The value propositions of multi-, cross-, and omni-channel retailing. Int. J. Retail. Distrib. Manag. 2018, 11, 1133-1152. [CrossRef]

35. Herhausen, D.; Binder, J.; Schoegel, M.; Herrmann, A. Integrating bricks with clicks: Retailer-level and channel-level outcomes of online-offline channel integration. J. Retail. 2015, 91, 309-325. [CrossRef]

36. Wollenburg, J.; Holzapfel, A.; Hübner, A.; Kuhn, H. Configuring Retail Fulfillment Processes for Omni-Channel Customer Steering. Int. J. Electron. Commer. 2018, 22, 540-575. [CrossRef]

37. Baxendale, S.; Macdonald, E.K.; Wilson, H.N. The impact of different touchpoints on brand consideration. J. Retail. 2015, 91, 235-253. [CrossRef]

38. Zhang, J.; Farris, P.W.; Irvin, J.W.; Kushwaha, T.; Steenburgh, T.J.; Weitz, B.A. Crafting Integrated Multichannel Retailing Strategies. J. Interact. Mark. 2010, 24, 168-180. [CrossRef]

39. Rai, H.B.; Mommens, K.; Verlinde, S.; Macharis, C. How does consumers' omnichannel shopping behaviour translate into travel and transport impacts? Case-study of a footwear retailer in Belgium. Sustainability 2019, 11, 2534.

40. Izmirli, D.; Ekren, B.; Kumar, V. Inventory Share Policy Designs for a Sustainable Omni-Chanel E-Commerce Network. Sustainability 2020, 12, 10022. [CrossRef]

41. Li, G.; Zhang, T.; Tayi, G.K. Inroad into omni-channel retailing: Physical showroom deployment of an online retailer. Eur. J. Oper. Res. 2020, 283, 676-691. [CrossRef]

42. Park, J.; Kim, R.B. The effects of integrated information \& service, institutional mechanism and need for cognition (NFC) on consumer omnichannel adoption Behaviour. Asia Pac. J. Mark. Logist. 2019, 33, 1355-5855.

43. Sousa, P.; Barbosa, M.; Oliveira, L.; Resende, P.; Rodrigues, R.; Moura, M.; Matoso, D. Challenges, Opportunities, and Lessons Learned: Sustainability in Brazilian Omnichannel Retail. Sustainability 2021, 13, 666. [CrossRef]

44. Dabholkar, P.A.; Sheng, X. The role of perceived control and gender in consumer reactions to download delays. J. Bus. Res. 2009, 62, 756-760. [CrossRef]

45. Alexander, B.; Cano, M.B. Futurising the physical store in the omnichannel retail environment. In Exploring Omnichannel Retailing; Springer: Cham, Switzerland, 2019; pp. 197-223.

46. Schoutteet, P.; Vanhaverbeke, L.; Buldeo Rai, H.; Verlinde, S.; Macharis, C. A consumer Behaviour typology based on temporal and spatial characteristics in an omnichannel retail environment. In Proceedings of the INFORMS 2017 Marketing Science Conference, Los Angeles, CA, USA, 8-10 June 2017; pp. 7-10.

47. Sulastini, S.; Fedorko, I.; Bačík, R.; Fedorko, R. An Analysis of online consumer shopping behaviour. Pol. J. Manag. Stud. 2018, 18, 338-349. [CrossRef]

48. Piotrowicz, W.; Cuthbertson, R. Exploring omnichannel retailing: Common expectations and diverse reality. In Exploring Omnichannel Retailing; Springer: Cham, Switzerland, 2019; pp. 1-10. 
49. Taylor, D.; Brockhaus, S.; Knemeyer, A.M.; Murphy, P. Omnichannel fulfillment strategies: Defining the concept and building an agenda for future inquiry. Int. J. Logist. Manag. 2019, 30, 863-891. [CrossRef]

50. Hickman, E.; Kharouf, H.; Sekhon, H. An omnichannel approach to retailing: Demystifying and identifying the factors influencing an omnichannel experience. Int. Rev. Retail. Distrib. Consum. Res. 2019, 30, 266-288. [CrossRef]

51. Fornell, C.; Larcker, D.F. Structural equation models with unobservable variables and measurement error: Algebra and statistics. J. Mark. Res. 1981, 18, 382-388. [CrossRef]

52. Caro, F.; Kök, A.G.; Martínez-de-Albéniz, V. The future of retail operations. Manuf. Serv. Oper. Manag. 2020, 22, 47-58. [CrossRef]

53. Gonda, G.; Gorgenyi-Hegyes, E.; Nathan, R.; Fekete-Farkas, M. Competitive Factors of Fashion Retail Sector with Special Focus on SMEs. Economies 2020, 8, 95. [CrossRef]

54. Krueger, J.; Omni-Channel Shoppers: An Emerging Retail Reality. Think with Google. 2015. Available online: http://think. storage.googleapis.com/docs/omni-channel-shoppers-an-emerging-retail-reality.pdf (accessed on 15 October 2021).

55. Mosquera, A.; Pascual, C.O.; Ayensa, E.J. Understanding the customer experience in the age of omni-channel shopping. Icono14 2017, 15, 5. [CrossRef]

56. Li, Y.; Liu, H.; Lim, E.T.; Goh, J.M.; Yang, F.; Lee, M.K. Customer's reaction to cross-channel integration in omnichannel retailing: The mediating roles of retailer uncertainty, identity attractiveness, and switching costs. Decis. Support Syst. 2018, 109, 50-60. [CrossRef]

57. Chen, Y.T.; Chou, T.Y. exploring the continuance intentions of consumers for B2C online shopping: Perspectives of fairness and trust. Online Inf. Rev. 2012, 36, 104-125. [CrossRef]

58. Gao, F.; Su, X. Omnichannel Retail Operations with Buy-Online-and-Pick-up-in-Store. Manag. Sci. 2017, 63, 2478-2492. [CrossRef]

59. Kotni, V.D.P. Paradigm Shift from Attracting Footfalls for Retail Store to Getting Hits for E-stores: An Evaluation of Decisionmaking Attributes in E-tailing. Glob. Bus. Rev. 2017, 18, 1215-1237. [CrossRef]

60. Melsted, L.R. Retailers Turn to Omnichannel Strategies to Remain Competitive. 2015. Available online: http:/ / www.forbes.com/ sites/samsungbusiness (accessed on 24 September 2020).

61. Piotrowicz, W.; Cuthbertson, R. Introduction to the special issue information technology in retail: Toward omnichannel retailing Int. J. Electron. Commer. 2014, 18, 5-16. [CrossRef]

62. Bendoly, E.; Blocher, J.D.; Bretthauer, K.M.; Krishnan, S.; Venkataramanan, M.A. Online/in-store integration and customer retention. J. Serv. Res. 2005, 7, 313-327. [CrossRef]

63. Lee, H.; Leonas, K. Consumer experiences, the key to survive in an omni-channel environment: Use of virtual technology. J. Text. Appar. Technol. Manag. 2018, 10, 3.

64. Zhang, M.; Ren, C.; Wang, G.A.; He, Z. The impact of channel integration on consumer responses in omni-channel retailing: The mediating effect of consumer empowerment. Electron. Commer. Res. Appl. 2018, 28, 181-193. [CrossRef]

65. Sharma, M.; Tiwari, P.; Chaubey, D. Summarizing Factors of Customer Experience and Building a Structural Model Using Total Interpretive Structural Modelling Technology. Glob. Bus. Rev. 2016, 17, 730-741. [CrossRef]

66. Verhoef, P.C.; Kannan, P.K.; Inman, J.J. From multi-channel retailing to omni-channel retailing: Introduction to the special issue on multi-channel retailing. J. Retail. 2015, 91, 174-181. [CrossRef]

67. Sekaran, U.; Bougie, R. Research Methods for Business: A Skill Building Approach; John Willey \& Sons: Hoboken, NJ, USA, 2003; pp. 50-78.

68. Lewis, J.; Whysall, P.; Foster, C. Drivers and Technology-Related Obstacles in Moving to Multichannel Retailing. Int. J. Electron. Commer. 2014, 18, 43-68. [CrossRef]

69. He, Y.; Xu, Q.; Wu, P. Omnichannel retail operations with refurbished consumer returns. Int. J. Prod. Res. 2019, 58, 271-290. [CrossRef]

70. Hair, J.F.; Anderson, R.E.; Tatham, R.L.; Black, W.C. Multivariate Data Analysis, 5th ed.; Macmillan: New York, NY, USA, 2006; pp. 25-45.

71. Saunders, M.; Lewis, P.; Thornhill, A. Research Methods for Business Students; Financial Times Prentice Hall: Hoboken, NJ, USA, 2003; pp. 40-67.

72. Sit, J.K.; Hoang, A.; Inversini, A. Showrooming and retail opportunities: A qualitative investigation via a consumer-experience lens. J. Retail. Consum. Serv. 2018, 40, 163-174. 